\title{
The effect of obesity on pregnancy outcomes among Australian Indigenous and non-Indigenous women
}

\section{Aaron P Thrift \\ $\mathrm{PhD}$ \\ NHMRC Early Career Fellow? \\ Leonie K Callaway \\ MBBS, PhD, FRACP \\ Professor and Head, ${ }^{2}$ and \\ Specialist in Internal and \\ Obstetric Medicine \\ 1 Population Health QIMR Berghofer Medical \\ Research Institute \\ Brisbane, QLD. \\ 2 Northern Academic Cluster, \\ School of Medicine, \\ University of Queensland, \\ Brisbane, QLD. \\ 3 Royal Brisbane and \\ Women's Hospital, \\ Brisbane, QLD. \\ aaron.thrift@ \\ qimrberghofer.edu.au}

MJA 2014; 201: 592-595 doi: 10.5694/mjal3.11170
liminating disparities between the health status of Indigenous and non-Indigenous Australians is a national priority. ${ }^{1}$ Obesity (body mass index [BMI] $\left.\geqslant 30.0 \mathrm{~kg} / \mathrm{m}^{2}\right)$ is a major contributor to chronic diseases. ${ }^{2,3}$ As obesity rates at all ages are higher among Indigenous Australians, ${ }^{4}$ obesity-related health disparities between Indigenous and non-Indigenous Australians are a public health concern.

In Australia, maternal overweight (BMI, $25.0-29.9 \mathrm{~kg} / \mathrm{m}^{2}$ ) and obesity are endemic in obstetric care. ${ }^{5}$ Consistent with national estimates, $432 \%$ of nonIndigenous women with singleton pregnancies at the Mater Mothers' Hospital in Brisbane between 1998 and 2009 were overweight or obese before pregnancy. ${ }^{5}$ The rate among Indigenous women was even higher, at $45 \% .5$ The association between overweight or obesity and pregnancy outcomes in Australia is well described for non-Indigenous women, but less comprehensively understood for Indigenous women. These studies have consistently shown that maternal overweight or obesity is associated with increased risk of maternal complications (including gestational diabetes and hypertensive disorders) and perinatal morbidity and mortality. Further, caesarean section rates are higher among overweight or obese women. ${ }^{5}$ However, ethnicity may modify the effect of overweight or obesity on maternal and infant outcomes, and its impact at the population level.6-8

We aimed to estimate the prevalence of maternal overweight or obesity among Indigenous and nonIndigenous women separately, and to examine whether the effect of overweight or obesity on maternal complications and perinatal outcomes is modified by Indigenous status.

\section{Methods}

We used aggregate data from the population-based Queensland Perinatal

\section{Abstrac}

Objective: To assess whether the effect of pre-pregnancy overweight or obesity on maternal complications and perinatal outcomes is modified by Indigenous status.

Design, participants and setting: Population-based study using de-identified aggregate data on pregnancies resulting in singleton births from Indigenous $(n=13582)$ and non-Indigenous $(n=241270)$ women from the Queensland Perinatal Data Collection, 1 July 2007 to 31 December 2011.

Main outcome measures: Prevalence of maternal (gestational diabetes mellitus [GDM], hypertensive disorders of pregnancy [HDP]) and delivery (preterm birth, birthweight, Apgar score) outcomes by Indigenous status and their association with pre-pregnancy body mass index.

Results: In 57\% of Indigenous pregnancies and $49 \%$ of non-Indigenous pregnancies, the mother was overweight, obese or severely obese. Prevalences of GDM, preterm birth and low birthweight were higher in Indigenous than nonIndigenous pregnancies. Overall rates of HDP were similar for Indigenous (5.1\%) and non-Indigenous pregnancies (4.9\%); however, rates were higher in normalweight Indigenous pregnancies (4.0\%) than in normal-weight non-Indigenous pregnancies (3.0\%). We found that overweight or obesity was associated with higher prevalence of GDM, HDP, high birthweight and low Apgar score. However, the associations with HDP, preterm birth and low birthweight were modified by Indigenous status ( $P$ for interaction, $<0.001$ for all). Overweight or obesity accounted for significantly fewer cases of HDP in Indigenous versus nonIndigenous pregnancies (population attributable fraction, 30\% v 41\%).

Conclusions: Maternal overweight or obesity is more common among Indigenous pregnancies, and Indigenous status may modify its association with pregnancy outcomes. Further research needs to explore the issue of increased insulin resistance and higher rates of HDP among normal-weight Indigenous women.

Data Collection (QPDC). The QPDC is a legislated statewide collection of information on all hospital and non-hospital births in Queensland of at least 20 weeks' gestation or at least $400 \mathrm{~g}$ birthweight. The study included 15050 singleton births to Queensland resident Indigenous women and 250798 to non-Indigenous women between 1 July 2007 and 31 December 2011. Data sourced for this study were sufficiently anonymised to protect patient privacy and confidentiality. Due to these aggregate data not being capable of identifying individual patients, a Public Health Act 2005 (Qld) application for release of these data was not required.

Self-reported pre-pregnancy height and weight are recorded at the first antenatal visit (in most cases, at around 12-16 weeks' gestation) and have been included in the QPDC since 1 July 2007.

In addition to demographic characteristics of the mother, the QPDC captures information on each birth, including maternal, peripartum and neonatal outcomes. We had the following maternal factors available for analysis: maternal age $(<20,20-24,25-$ $29,30-34,35-39$, and $\geqslant 40$ years); nulliparity (no, yes); remoteness of usual residence (Accessibility/Remoteness Index of Australia [ARIA+]: major city, inner regional, outer regional, remote, and very remote); maternal smoking during pregnancy (no, yes); mode of delivery (vaginal, caesarean section); pre-existing diabetes mellitus (no, yes); pre-existing hypertension (no, yes); hypertensive disorders of pregnancy (HDP; no, yes); and gestational diabetes mellitus (GDM; no, yes). We had the following infant factors available for analysis: gestational age $(<28,28-31$, $32-36,37-41$, and $\geqslant 42$ weeks); birthweight $(<2500 \mathrm{~g}, 2500-2999 \mathrm{~g}, 3000$ $3499 \mathrm{~g}, 3500-3999 \mathrm{~g}, 4000-4499 \mathrm{~g}$, and $\geqslant 4500 \mathrm{~g}$ ); and Apgar scores at 1 and 5 minutes (score: 0-3, 4-6, and 7-10). To 
encompass the maternal and infant factors analysed, data are referred to as "Indigenous pregnancies" and "non-Indigenous pregnancies".

\section{Statistical analysis}

Associations between BMI and maternal and infant outcomes were assessed using multivariable log-link Poisson models to estimate prevalence ratios (PRs) and 95\% confidence intervals adjusted for maternal age, nulliparity, ARIA+ category and smoking status. Additional adjustment for year did not change the observed PRs, so it was not included in the final model. We assessed effect modification by Indigenous status by including an interaction term in the models. Significance of the interaction term was determined by a likelihood ratio test. In supplementary analyses, we estimated adjusted populationattributable fractions (PAFs) for each outcome associated with overweight or obesity, 9,10 and performed analyses additionally stratified by age $(<25$, $\geqslant 25$ years), nulliparity and smoking status. Analyses were conducted using SAS 9.3 (SAS Institute) and tests for statistical significance were twosided at $\alpha=0.05$.

\section{Results}

Of 265848 births, 13582 to Indigenous women and 241270 to non-Indigenous women had associated maternal BMI recorded in the QPDC. The percentage of missing BMI data in the QPDC was highest in the first 2 years, but decreased from $11 \%$ in 2007 to $2 \%$ in 2011 . Each year, the proportion of missing BMI data was higher for Indigenous than non-Indigenous pregnancies (2007, 23\% v 10\%; 2011, $4 \%$ v $2 \%$ ).

In $57 \%$ of Indigenous pregnancies and $49 \%$ of non-Indigenous pregnancies, the mother was overweight, obese or severely obese (Appendix 1 , online at mja.com.au). The proportion of pregnancies occurring in overweight, obese or severely obese women remained essentially unchanged over time. BMI and Indigenous status were statistically significantly associated with age, parity, ARIA+ category and smoking during pregnancy.

\section{Maternal outcomes}

Prevalence of GDM was higher in Indigenous than non-Indigenous pregnancies $(6.9 \% \mathrm{v} 5.5 \%, P<0.001)$, while HDP occurred in $5.0 \%$ of all pregnancies $(P=0.14)$. Overall rates of HDP were similar for Indigenous (5.1\%) and non-Indigenous (4.9\%) pregnancies; however, rates were higher in normal-weight Indigenous pregnancies $(4.0 \%)$ versus normalweight non-Indigenous pregnancies (3.0\%).

GDM prevalence increased with increasing BMI (Box; Appendix 2, online at mja.com.au); the association did not vary by Indigenous status $(P$ for interaction, 0.45). In contrast, the PR for HDP associated with obesity was significantly higher for nonIndigenous than Indigenous pregnancies ( $P$ for interaction, $<0.001$ ). Prevalence of HDP was significantly lower in pregnancies among underweight women than in those among women with normal BMI.

\section{Delivery outcomes}

The prevalence of caesarean section was higher among non-Indigenous than Indigenous women (33\% v 25\%; $P<0.001)$. Overweight, obese or severely obese women's pregnancies were more likely to end in a caesarean section than pregnancies in women with normal BMI, regardless of Indigenous status ( $P$ for interaction, 0.13).

Preterm births (spontaneous or medically induced) were more likely among Indigenous than nonIndigenous pregnancies. Prevalence of preterm birth before 32 weeks was twofold higher for pregnancies among underweight Indigenous women; however, there was no consistent association between increasing BMI and preterm birth in either group. We found significantly lower prevalence of preterm birth before 37 weeks for pregnancies in overweight or obese Indigenous women, but no association for pregnancies in nonIndigenous women ( $P$ for interaction, $<0.001$ ).

Birthweight was lower than $2500 \mathrm{~g}$ in $9 \%$ of babies born to Indigenous women, and $4 \%$ born to non-Indigenous women. The prevalence of low birthweight was higher in underweight women's pregnancies; however, while BMI was inversely associated with low birthweight overall, the magnitude of the association was stronger for Indigenous than non-Indigenous pregnancies ( $P$ for interaction, <0.001).

Pregnancies in underweight Indigenous women had a higher prevalence of low Apgar score at 5 minutes, while obesity was associated with a low Apgar score at 1 and 5 minutes in all pregnancies.

\section{Supplemental analyses}

We calculated PAFs for each outcome associated with BMI $\geqslant 25.0 \mathrm{~kg} / \mathrm{m}^{2}$. The PAF for GDM was higher for Indigenous (52\%; 95\% CI, 48\%-56\%) than non-Indigenous (39\%; 95\% CI, $38 \%-40 \%$ ) pregnancies. Likewise, the PAF for high birthweight was higher for Indigenous (41\%; 95\% CI, 37\%$45 \%$ ) than non-Indigenous ( $25 \%$; $95 \%$ CI, 24\%-25\%) pregnancies. In contrast, the PAF for HDP was lower for Indigenous (30\%; 95\% CI, 24\%-36\%) than non-Indigenous (41\%; 95\% CI, $40 \%-42 \%$ ) pregnancies.

We observed similar results when we additionally stratified by age, nulliparity and smoking status, and when we excluded births from women with either pre-existing diabetes or hypertension (data not shown).

\section{Discussion}

Almost half of all singleton babies born in Queensland between 2007 and 2011 were born to overweight or obese women, with the highest rates observed in Indigenous women. Consistent with the Australian obstetric population as a whole, ${ }^{11} 5 \%$ and $6 \%$ of pregnancies in our study involved HDP and GDM, respectively. Compared with pregnancies in normal-weight non-Indigenous women, the prevalence of HDP or GDM was more than fourfold higher in pregnancies in severely obese nonIndigenous women; $40 \%$ of cases of HDP and GDM in non-Indigenous pregnancies may be attributed to overweight or obesity.

To the best of our knowledge, the current study is the first to show that the magnitude of the association between BMI and HDP in Australian women is modified by Indigenous status. Prevalence of HDP was only 
Adjusted prevalence ratios* and 95\% confidence intervals for maternal and delivery outcomes, according to Indigenous status and body mass index (BMI) category

\begin{tabular}{|c|c|c|c|c|c|c|c|c|c|c|c|}
\hline & \multicolumn{5}{|c|}{ Indigenous $(n=13582)$} & \multicolumn{5}{|c|}{ Non-Indigenous $(n=241270)$} & \multirow[b]{2}{*}{$\begin{array}{c}P \text { for } \\
\text { interaction }\end{array}$} \\
\hline & Underweight & Normal $^{\dagger}$ & Overweight & Obese & $\begin{array}{l}\text { Severely } \\
\text { obese }\end{array}$ & Underweight & Normal $^{\dagger}$ & Overweight & Obese & $\begin{array}{l}\text { Severely } \\
\text { obese }\end{array}$ & \\
\hline No. & 857 & 4966 & 3776 & 3353 & 630 & 10864 & 112385 & 66729 & 43837 & 7455 & \\
\hline \multicolumn{12}{|l|}{ Maternal outcomes } \\
\hline GDM & $\begin{array}{c}1.17 \\
(0.77-1.78)\end{array}$ & 1.00 & $\begin{array}{c}1.94 \\
(1.58-2.38)\end{array}$ & $\begin{array}{c}3.00 \\
(2.47-3.63)\end{array}$ & $\begin{array}{c}4.44 \\
(3.48-5.67)\end{array}$ & $\begin{array}{c}1.00 \\
(0.90-1.12)\end{array}$ & 1.00 & $\begin{array}{c}1.65 \\
(1.58-1.73)\end{array}$ & $\begin{array}{c}2.76 \\
(2.64-2.88)\end{array}$ & $\begin{array}{c}4.47 \\
(4.18-4.78)\end{array}$ & 0.45 \\
\hline HDP & $\begin{array}{c}0.55 \\
(0.34-0.88)\end{array}$ & 1.00 & $\begin{array}{c}1.44 \\
(1.18-1.75)\end{array}$ & $\begin{array}{c}2.00 \\
(1.64-2.43)\end{array}$ & $\begin{array}{c}2.12 \\
(1.53-2.94)\end{array}$ & $\begin{array}{c}0.74 \\
(0.65-0.84)\end{array}$ & 1.00 & $\begin{array}{c}1.76 \\
(1.68-1.85)\end{array}$ & $\begin{array}{c}3.12 \\
(2.97-3.27)\end{array}$ & $\begin{array}{c}4.95 \\
(4.60-5.32)\end{array}$ & $<0.001$ \\
\hline \multicolumn{12}{|l|}{ Delivery outcomes } \\
\hline Caesarean section & $\begin{array}{c}0.91 \\
(0.77-1.08)\end{array}$ & 1.00 & $\begin{array}{c}1.18 \\
(1.08-1.29)\end{array}$ & $\begin{array}{c}1.32 \\
(1.21-1.44)\end{array}$ & $\begin{array}{c}1.81 \\
(1.58-2.07)\end{array}$ & $\begin{array}{c}0.89 \\
(0.86-0.93)\end{array}$ & 1.00 & $\begin{array}{c}1.17 \\
(1.15-1.19)\end{array}$ & $\begin{array}{c}1.36 \\
(1.33-1.39)\end{array}$ & $\begin{array}{c}1.59 \\
(1.54-1.65)\end{array}$ & 0.13 \\
\hline $\begin{array}{l}\text { Preterm birth < } 32 \\
\text { weeks }\end{array}$ & $\begin{array}{c}1.98 \\
(1.36-2.88)\end{array}$ & 1.00 & $\begin{array}{c}1.05 \\
(0.78-1.40)\end{array}$ & $\begin{array}{c}0.87 \\
(0.63-1.20)\end{array}$ & $\begin{array}{c}1.28 \\
(0.75-2.18)\end{array}$ & $\begin{array}{c}1.45 \\
(1.22-1.71)\end{array}$ & 1.00 & $\begin{array}{c}0.97 \\
(0.87-1.07)\end{array}$ & $\begin{array}{c}1.05 \\
(0.94-1.17)\end{array}$ & $\begin{array}{c}1.36 \\
(1.11-1.68)\end{array}$ & 0.40 \\
\hline $\begin{array}{l}\text { Preterm birth < } 37 \\
\text { weeks }\end{array}$ & $\begin{array}{c}1.51 \\
(1.25-1.81)\end{array}$ & 1.00 & $\begin{array}{c}0.83 \\
(0.72-0.95)\end{array}$ & $\begin{array}{c}0.69 \\
(0.59-0.80)\end{array}$ & $\begin{array}{c}0.76 \\
(0.57-1.01)\end{array}$ & $\begin{array}{c}1.39 \\
(1.30-1.49)\end{array}$ & 1.00 & $\begin{array}{c}0.97 \\
(0.93-1.01)\end{array}$ & $\begin{array}{c}1.00 \\
(0.96-1.05)\end{array}$ & $\begin{array}{c}1.09 \\
(0.99-1.19)\end{array}$ & $<0.001$ \\
\hline $\begin{array}{l}\text { Low birthweight } \\
(<2500 \mathrm{~g})\end{array}$ & $\begin{array}{c}1.56 \\
(1.31-1.86)\end{array}$ & 1.00 & $\begin{array}{c}0.68 \\
(0.59-0.78)\end{array}$ & $\begin{array}{c}0.49 \\
(0.42-0.58)\end{array}$ & $\begin{array}{c}0.49 \\
(0.34-0.69)\end{array}$ & $\begin{array}{c}1.80 \\
(1.68-1.93)\end{array}$ & 1.00 & $\begin{array}{c}0.81 \\
(0.77-0.85)\end{array}$ & $\begin{array}{c}0.77 \\
(0.73-0.81)\end{array}$ & $\begin{array}{c}0.84 \\
(0.75-0.94)\end{array}$ & $<0.001$ \\
\hline $\begin{array}{l}\text { High birthweight } \\
(\geqslant 4000 \mathrm{~g})\end{array}$ & $\begin{array}{c}0.65 \\
(0.44-0.97)\end{array}$ & 1.00 & $\begin{array}{c}1.70 \\
(1.46-1.99)\end{array}$ & $\begin{array}{c}2.36 \\
(2.03-2.75)\end{array}$ & $\begin{array}{c}3.26 \\
(2.64-4.03)\end{array}$ & $\begin{array}{c}0.50 \\
(0.46-0.54)\end{array}$ & 1.00 & $\begin{array}{c}1.44 \\
(1.40-1.48)\end{array}$ & $\begin{array}{c}1.82 \\
(1.77-1.87)\end{array}$ & $\begin{array}{c}2.27 \\
(2.16-2.39)\end{array}$ & $<0.001$ \\
\hline $\begin{array}{l}\text { 1-minute Apgar } \\
\text { score }<7\end{array}$ & $\begin{array}{c}1.22 \\
(0.97-1.52)\end{array}$ & 1.00 & $\begin{array}{c}1.09 \\
(0.95-1.25)\end{array}$ & $\begin{array}{c}1.23 \\
(1.06-1.42)\end{array}$ & $\begin{array}{c}1.62 \\
(1.28-2.05)\end{array}$ & $\begin{array}{c}0.92 \\
(0.86-0.99)\end{array}$ & 1.00 & $\begin{array}{c}1.13 \\
(1.09-1.17)\end{array}$ & $\begin{array}{c}1.27 \\
(1.22-1.32)\end{array}$ & $\begin{array}{c}1.63 \\
(1.52-1.74)\end{array}$ & 0.20 \\
\hline $\begin{array}{l}\text { 5-minute Apgar } \\
\text { score }<7\end{array}$ & $\begin{array}{c}1.71 \\
(1.15-2.54)\end{array}$ & 1.00 & $\begin{array}{c}1.06 \\
(0.80-1.42)\end{array}$ & $\begin{array}{c}1.22 \\
(0.92-1.63)\end{array}$ & $\begin{array}{c}1.85 \\
(1.18-2.88)\end{array}$ & $\begin{array}{c}0.95 \\
(0.81-1.11)\end{array}$ & 1.00 & $\begin{array}{c}1.02 \\
(0.94-1.10)\end{array}$ & $\begin{array}{c}1.26 \\
(1.16-1.36)\end{array}$ & $\begin{array}{c}1.70 \\
(1.46-1.98)\end{array}$ & 0.16 \\
\hline
\end{tabular}

$\mathrm{GDM}=$ gestational diabetes mellitus. $\mathrm{HDP}=$ hypertensive disorders of pregnancy. Underweight $=\mathrm{BMI},<18.0 \mathrm{~kg} / \mathrm{m}^{2}$. Normal $=\mathrm{BMI}, 18.0-24.9 \mathrm{~kg} / \mathrm{m}^{2} .0 v e r w e i g h t=\mathrm{BMI}, 25.0-29.9 \mathrm{~kg} / \mathrm{m}^{2}$.

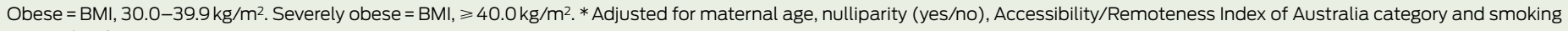
status. † Reference category.

twofold higher in obese Indigenous women's pregnancies, and overweight or obesity accounted for only $30 \%$ of HDP in Indigenous pregnancies. Similar ethnic differences have been observed in the United States and the United Kingdom.6,7 In contrast, while the association between maternal overweight or obesity and GDM was not modified by Indigenous status, the burden of GDM associated with overweight or obesity was significantly higher for Indigenous pregnancies.

For high birthweight, the magnitude of the association with obesity was stronger for Indigenous pregnancies, and overweight or obesity accounted for a greater proportion of high birthweight babies born to Indigenous than non-Indigenous women. We found no association between overweight or obesity and preterm birth in non-Indigenous pregnancies; however, prevalence of preterm birth before 37 weeks' gestation was lower in overweight or obese Indigenous women's pregnancies. Similar disparities have been reported in three US studies, where the risk of preterm birth was lower among obese black women and higher among obese white women.12-14 While studies, including ours, have found higher prevalence of preterm birth in underweight women's pregnancies, the association with overweight or obesity remains controversial. Two meta-analyses reported a modest increased risk of preterm birth associated with obesity, 15,16 although literature shows conflicting results.

The biological basis for associations between overweight or obesity and adverse pregnancy outcomes are unclear. The varying effects by ethnicity, however, may be due to differences in body fat distribution, as Indigenous women have more central body fat for a given BMI than non-Indigenous women. ${ }^{17,18}$ Furthermore, lean Indigenous women are more likely to be insulin resistant, ${ }^{19}$ and obesity has been shown to have a greater effect on insulin resistance in non-white than in white women. ${ }^{8,20}$ It is also possible that there may be genetic differences between Indigenous and non-Indigenous women that explain different rates of pre-eclampsia, and this is an important area for further study. There may also be different behaviours in the younger, normalweight group of Indigenous women that we cannot measure (eg, shorter periods of sperm antigen exposure, higher burdens of inflammation and endothelial dysfunction relating to chronic infections).

The strengths of our study include the large population-based cohort and collection of information on a range of potential confounders. While no studies have assessed the completeness and accuracy of the QPDC as a whole, validation studies of a similar database in New South Wales report high levels of accuracy for infant and maternal outcomes. ${ }^{21}$ More missing BMI data from Indigenous pregnancies, likely due to later presentation for antenatal care, ${ }^{22}$ may be a limitation. Although we found differences between the characteristics of women with and without BMI data, our results were unchanged when we restricted our analyses to years with more complete data. BMI was based on recalled height and weight; however, a previous study in a subset of 
mothers giving birth in Queensland has shown high correlation $(r=0.95)$ between maternal estimate of prepregnancy weight and weight recorded at the first antenatal visit, ${ }^{23}$ and any misclassification would attenuate the associations here. It is unclear whether such misclassification would have differed by Indigenous status. Another possible limitation is the use of self-reported Indigenous status. Indigenous mothers who were not enumerated in the QPDC may have influenced the true association with BMI. While we adjusted for potential confounders, we cannot completely exclude residual confounding. Compared with non-Indigenous women, Indigenous women are younger and tend to be thin when they have their first baby; however, they tend to have more children and gain a lot more weight. ${ }^{11}$ Young age and parity are also risk factors for HDP and may confound the associations with obesity. The higher rates of caesarean section for non-Indigenous women may be due to private health insurance status; however, we did not have data on private health insurance status in this study. Finally, because it is possible that subgroups of women may be more likely than others to be screened, the observed effect for obesity may actually underestimate the true effect as the nondisease groups would be very likely to include women with undiagnosed disease. Confounding by indication could have occurred, as obese women may be more likely to be screened for maternal health indicators than nonobese women. It is unclear whether screening is more or less likely to occur in Indigenous women.
In summary, maternal overweight or obesity is common in obstetric care and is associated with poor pregnancy outcomes. Elucidating the reasons for the varying effects by Indigenous status will help in understanding the pathways leading to these events.

Competing interests: No relevant disclosures.

Received 10 Sep 2013, accepted 15 Jul 2014.

1 Australian Government. Closing the gap on Indigenous disadvantage: the challenge for Australia. Canberra: Commonwealth of Australia, 2009. http://www.dss.gov.au/sites/ default/files/documents/05_2012/closing_ the_gap.pdf (accessed Jul 2014).

2 Must A, Spadano J, Coakley EH, et al. The disease burden associated with overweight and obesity. JAMA 1999; 282: 1523-1529.

3 Renehan AG, Tyson M, Egger M, et al. Body-mass index and incidence of cancer: a systematic review and meta-analysis of prospective observational studies. Lancet 2008; 371: 569-578

4 Australian Bureau of Statistics. National Aboriginal and Torres Strait Islander Health Survey, 2004-05. Canberra: ABS, 2006. (ABS Cat. No. 4715.0.) http://www.abs.gov.au/ ausstats/abs@.nsf/mf/4715.0 (accessed Jul 2014).

5 McIntyre HD, Gibbons KS, Flenady VJ, Callaway LK. Overweight and obesity in Australian mothers: epidemic or endemic? Med J Aust 2012. 196: 184-188.

6 Ramos GA, Caughey AB. The interrelationship between ethnicity and obesity on obstetric outcomes. Am J Obstet Gynecol 2005; 193 (3 Pt 2): 1089-1093.

7 Oteng-Ntim E, Kopeika J, Seed P, et al. Impact of obesity on pregnancy outcome in different ethnic groups: calculating population attributable fractions. PLOS One 2013; 8 : e53749.

8 Retnakaran R, Hanley AJ, Connelly PW, et al. Ethnicity modifies the effect of obesity on insulin resistance in pregnancy: a comparison of Asian, South Asian, and Caucasian women.J Clin Endocrinol Metab 2006; 91: 93-97.

9 Bruzzi P, Green SB, Byar DP, et al. Estimating the population attributable risk for multiple risk factors using case-control data. Am J Epidemiol 1985; 122: 904-914.

10 Graubard BI, Fears TR. Standard errors for attributable risk for simple and complex sample designs. Biometrics 2005; 61: 847-855.
11 Australian Institute of Health and Welfare, Li Z, Zeki R, et al. Australia's mothers and babies 2010. Canberra: AlHW, 2012. (AlHW Cat. No. PER 57; Perinatal Statistics Series No. 27.) http://www.aihw.gov.au/publicationdetail/?id=60129542376 (accessed Jul 2014).

12 de Jongh BE, Paul DA, Hoffman M, Locke R. Effects of pre-pregnancy obesity, race/ethnicity and prematurity. Matern Child Health J 2014; 18: 511-517.

13 Torloni MR, Fortunato SJ, Betrán AP, et al. Ethnic disparity in spontaneous preterm birth and maternal pre-pregnancy body mass index. Arch Gynecol Obstet 2012; 285: 959-966.

14 Salihu HM, Luke S, Alio AP, et al. The superobese mother and ethnic disparities in preterm birth. $J$ Natl Med Assoc 2009; 101: 1125-1131.

15 Torloni MR, Betrán AP, Daher S, et al. Maternal $\mathrm{BMI}$ and preterm birth: a systematic review of the literature with meta-analysis. J Matern Fetal Neonatal Med 2009; 22: 957-970.

16 McDonald SD, Han Z, Mulla S, et al. Overweight and obesity in mothers and risk of preterm birth and low birth weight infants: systematic review and meta-analyses. BMJ 2010; 341: c3428.

17 Piers LS, Rowley KG, Soares MJ, O'Dea K. Relation of adiposity and body fat distribution to body mass index in Australians of Aboriginal and European ancestry. Eur J Clin Nutr 2003; 57 : 956-963.

18 Kondalsamy-Chennakesavan S, Hoy WE, Wang Z, et al. Anthropometric measurements of Australian Aboriginal adults living in remote areas: comparison with nationally representative findings. Am J Hum Biol 2008; 20: 317-324.

19 Maple-Brown L, Cunningham J, Dunne K, et al. Complications of diabetes in urban Indigenous Australians: the DRUID study. Diabetes Res Clin Pract 2008; 80: 455-462.

20 Palaniappan LP, Carnethon MR, Fortmann SP. Heterogeneity in the relationship between ethnicity, BMI, and fasting insulin. Diabetes Care 2002; 25: 1351-1357.

21 Taylor L, Bajuk B, Vincent T, Giffin M. Mothers and babies 2004. NSW Public Health Bull 2005; 16: 1-139.

22 Rumbold AR, Cunningham J. A review of the impact of antenatal care for Australian Indigenous women and attempts to strengthen these services. Matern Child Health J 2008; 12: 83-100.

23 Mamun AA, Lawlor DA, O'Callaghan MJ, et al. Family and early life factors associated with changes in overweight status between ages 5 and 14 years: findings from the Mater University Study of Pregnancy and its outcomes. Int J Obes (Lond) 2005; 29: 475-482. 